\title{
Flap Complications from Femtosecond Laser-assisted in Situ Keratomileusis
}

\author{
Steven H Tucker $^{1}$ and Priyanka Sood ${ }^{2}$ \\ 1. Emory Eye Center, Atlanta, GA, USA; 2. Emory University Hospital Midtown, Atlanta, GA, USA
}

DOI: httpS://doi.org/10.17925/USOR.2019.12.1.21

$\mathrm{B}$ ackground: LASIK has been the primary refractive surgical procedure for the past three decades. More than 15 million patients have undergone the surgery, which has a low complication rate of approximately $1 \%$. Purpose: To review common flap complications of femtosecond laser-assisted in situ keratomileusis (LASIK) and discuss management options. Methods: The PubMed database was used to identify relevant published literature. The search was conducted using LASIK flap complications as a search term, as well as LASIK and all the associated complications that have been noted in the results section. Results: Flap creation is a pivotal step in LASIK surgery. Femtosecond laser-assisted flap creation allows a more reliable and reproducible flap and has led to more predictable and safe lamellar dissections. However, intraoperative complications can still occur and include issues with suction, epithelial defects, opaque bubble layer, vertical gas breakthrough, anterior chamber gas bubble, flap tears, bleeding, and interface debris. Postoperative complications can include striae, diffuse lamellar keratitis, rainbow glare, dry eye, dislocated flaps, keratitis, epithelial ingrowth, transient light-sensitivity syndrome, interface haze, and corneal ectasia. Conclusions: While femtosecond laser use has decreased several complications that are prominent with microkeratome use (e.g. buttonholes, incomplete flaps, epithelial erosions), it has introduced others (e.g. rainbow glare, opaque bubble layer, vertical gas breakthrough). Predictability has however, continued to improve over time, creating a safer LASIK procedure. Surgeons who understand all possible LASIK complications and have good knowledge of the laser mechanisms specific to the unit they are using, can help safely deliver reliable outcomes for their patients.

\section{Keywords}

Femtosecond laser-assisted flap creation, laser-assisted in situ keratomileusis, LASIK, LASIK complications

Disclosures: Steve Tucker and Priyanka Sood have no relevant conflicts of interest to declare.

Review Process: Double-blind peer review.

Compliance with Ethics: This study involves a review of the literature and did not involve any studies with human or animal subjects performed by any of the authors.

Authorship: The named authors meet the International Committee of Medical Journal Editors (ICMJE) criteria for authorship of this manuscript, take responsibility for the integrity of the work as a whole, and have given final approval for the version to be published.

Received: January 15, 2019

Accepted: April 1, 2019

Citation: US Ophthalmic Review. 2019;12(1):21-7

Corresponding Author: Priyanka Sood, Emory University Hospital Midtown, The Emory Clinic Building B, 1365B Clifton Road, NE Atlanta, Georgia 30322, USA. E:psood2@emory.edu

Support: No funding was received in the publication of this article.
Lamellar procedures have their origins in the 1960s, when they were introduced by Barraquer in Columbia. ${ }^{1}$ In the 1990s, Pallikaris and Buratto introduced the concept of combining a lamellar procedure with surface ablation excimer lasers, ${ }^{2,3}$ giving rise to laser-assisted in situ keratomileusis (LASIK) surgery. Several iterations and techniques have been developed since then, and over the last three decades LASIK has become one of the most common and successful elective refractive procedures performed. ${ }^{4,5}$ Since its inception, more than 15 million patients have undergone the surgery. ${ }^{6}$ Overall, the complication rate from LASIK is low, with reports ranging from $<1-1.8 \% .^{7-9}$

The first critical step in LASIK is creation of the corneal flap. The LASIK flap is paramount to the procedure and allows for quick visual recovery with little pain, ${ }^{10}$ but is also a major source of complications. There are two main methods for creating corneal flaps. The first involves using a mechanical microkeratome with an oscillating blade. ${ }^{11}$ The second utilizes a femtosecond laser with a focusable, infrared-spectrum photodisruptive laser, which forms cavitation bubbles that spread to produce a dissected corneal flap. ${ }^{12}$

Advantages of femtosecond laser flap creation include reduced variation in flap thickness and increased repeatability. ${ }^{13}$ Some studies have suggested better final visual acuity, ${ }^{14}$ lower intraocular pressure (IOP) during the flap creation, ${ }^{15}$ and lower incidence of dry eye. ${ }^{16}$ Additionally, some prominent microkeratome complications including free/incomplete flaps, buttonholes, and epithelial erosions are less common due to the femtosecond's precision. ${ }^{14}$ However, disadvantages of the femtosecond include transient light sensitivity, ${ }_{1}^{17}$ diffuse lamellar keratitis ${ }^{18}$ rainbow glare, ${ }_{19}^{19}$ opaque bubble layer, ${ }^{20}$ and cost. ${ }^{21}$ Both device classes are still used, but femtosecond has grown in popularity over time. Several femtosecond laser systems are approved by The Food and Drug Administration (FDA) for LASIK use. However, discussion on each individual system is beyond the scope of this review.

Understanding, avoiding and managing potential femtosecond flap complications is essential for anyone performing femtosecond-assisted LASIK. This review will discuss intraoperative and postoperative flap complications associated with femtosecond-assisted LASIK using PubMedidentified relevant published literature. The PubMed search was conducted using "LASIK flap 
complications" as a primary search term, as well as "LASIK" alongside the various associated complications that will be discussed later.

\section{Intraoperative complications Suction loss}

While not unique to femtosecond flap creation, issues with suction are one of the most commonly encountered problems. Reported rates of suction loss range from $0.06-0.8 \% .{ }^{22}$ Given the unique lamellar cutting ability of femtosecond lasers, suction issues can often be overcome without compromising patient outcomes. ${ }^{23}$ Unlike keratome flaps, procedures are not automatically aborted when suction loss occurs. ${ }^{4}$

Predisposing factors for issues with suction include flat corneas (mean curvature of $<42$ diopters), deep-set eyes, narrow palpebral fissures, patient positioning, lid squeezing, and patient movement of head or eyes. ${ }^{4,5}$ In these cases, it is essential to ensure adequate initial suction and careful observation during docking. Once central suction is visualized, attention should turn to the periphery to evaluate for a peripheral asymmetric meniscus, which is one of the first signs of suction loss. ${ }^{5}$ If it occurs early in treatment, immediate cessation is required. Later in the treatment, there should still be very low threshold to stop and redock. A benefit of the femtosecond laser is that the laser cut can be repeated (at the same depth _with the same suction cone), given the reliability of the cutting depth, if no manufacture warnings are present. When completing a partially cut flap, it is essential to ensure that each aspect of the cut (vertical pocket, side cut, lamellar cut) is complete and contiguous. If the suction loss occurred during the raster stage, most surgeons use the "pocket off" setting since the vertical limbal pocket, which absorbs cavitation bubbles, is already complete for the second cut. If the suction loss occurs during the sidecut stage (after completion of raster cut), flap diameter can be reduced by $0.2-0.5 \mathrm{~mm}$ depending on the manufacturer. ${ }^{23}$ An initial inferior flap dissection and lift away from the hinge after a recut is preferred since the cut terminates inferiorly. This is thought to decrease risk of flap tear. ${ }^{23}$ One study reported that multiple cuts with the femtosecond laser do not cause an irregular stromal bed. ${ }^{24}$ Tomita et al. found that in cases with suction loss, $97.2 \%$ achieved an uncorrected distance visual acuity of $20 / 20$ or better and $100 \%$ achieved a corrected distance visual acuity of 20/20 or better. ${ }^{23}$ If suction cannot be re-established after a partial cut, experts vary on their recommendation for timing of subsequent advanced surface ablation. some recommend waiting as little as one week with use of mitomycin C to decrease stromal haze, ${ }^{4}$ while others recommend waiting two months prior to attempting surface ablation, to decrease the healing response and reduce the risk of stromal haze. ${ }^{5}$ It is difficult to know the exact frequency of suction loss resulting in abandonment of the procedure; however, Brenner et al. reported a rate of $0.003 \%$ for aborted femtosecond LASIK flaps in over 7,000 LASIK cases and showed good visual outcomes after subsequent advanced surface ablation..$^{25}$

\section{Epithelial defects}

Epithelial defects are defined in most studies as an area $2.0 \mathrm{~mm} \times 2.0 \mathrm{~mm}$ with a break in the epithelium or loose epithelial cells. Defect frequencies have ranged from $0-0.6 \%$ in femtosecond studies. ${ }^{26,27}$ While less common with femtosecond technology, the pocket and shock waves can predispose to epithelial defects. Additionally, inserting the dissecting spatula at the flap edge has the potential to cause a defect. ${ }^{5}$ Risk factors include anterior basement membrane dystrophy, older age, large flap diameter, recurrent erosion syndrome, or excessive use of topical anesthetic.
Intraoperative management is unchanged but postoperative management may include a bandage contact lens and antibiotics. Additionally, topical corticosteroids should be used more frequently (up to every 1-2 hours) to help prevent development of diffuse lamellar keratitis (DLK). ${ }^{28,29}$ Finally, patients should be followed more closely until the defect heals, and bandage contact lens use can be discontinued.

\section{Opaque bubble layer}

opaque bubble layer (OBL) occurs when cavitation gas bubbles formed by the femtosecond laser expand in the cleavage plane and become trapped in the anterior stroma. ${ }^{30}$ Visualizing this layer is a well-known finding intraoperatively with all femtosecond platforms. ${ }^{4}$ The incidence of OBL when using the laser for flap creation ranges from $5-48 \%{ }^{31}$

Excessive $\mathrm{OBL}$ can lead to interference with many parts of the procedure including flap creation, residual stromal bed measurement, and excimer laser tracking systems.,30 Risk factors include patients with thicker corneas $^{30}$ and older patients with denser peripheral collagen that prevents the escape of the bubbles. ${ }^{32}$ Preventative measures include decreasing flap size if excessive scleral show is noted at the time of suction ring application and adjusting laser settings. Several laser settings can be altered including utilizing less line/spot spacing, larger pocket size, higher energy levels, and using a lighter applanation technique, whereby a complete meniscus is formed but not fully extended to the suction ring edge. One challenge of OBL is a tight flap adhesion which puts the patient at risk of flap tears during dissection. ${ }^{33}$ Management includes using a flap-lifting spatula with downward pressure to sweep and spread the bubbles along the cleavage plain. ${ }^{4}$ When present, some surgeons prefer to let the bubbles clear before proceeding which may take up to 30 minutes or more. No significant impact on visual acuity outcomes has been found. ${ }^{5,30}$

\section{Vertical gas breakthrough}

Vertical gas breakthrough can occur when cavitation bubbles dissect superiorly toward Bowman's layer and through the epithelium. A buttonhole is created with a deep black appearance and the procedure should be terminated to prevent epithelial ingrowth and scarring. ${ }^{34}$ subsequent surface ablative procedures after healing can be performed to remove the spot and treat the refractive error. ${ }^{25}$ If the bubbles stop beneath Bowman's membrane, a whitish appearance may present but the procedure can typically be continued once a complete buttonhole is excluded. ${ }^{4}$ Frequency in large studies have shown a $0.3 \%$ risk of split flap and up to a $1.3 \%$ risk of a pseudo-buttonhole. ${ }^{35}$ Risk factors include a thin flap, corneal scar, previous radial keratotomy surgery, and microscopic breaks in Bowman's membrane. ${ }^{4,5}$

\section{Anterior chamber gas bubble}

Evidence suggests that bubbles can enter the anterior chamber via pathways such as Schlemm's canal, the trabecular meshwork, or pulses misdirected to the aqueous humor. ${ }^{4,36}$ There is correlation between this finding and the femtosecond dissection being too close to the limbus. This type of dissection can also occur with large flaps, small corneas, or high suction pressure. ${ }^{32} \mathrm{~A}$ smaller diameter flap should be considered if scleral show is excessive after applying suction. ${ }^{4}$ The main concern and complication from anterior chamber gas bubble is the ability to use the pupil-tracking function of excimer lasers. Most surgeons will test the pupil-tracking function and proceed if there is no issue or elect to observe until clearing if tracking is affected..$^{5}$ In our experience, bubbles can take anywhere from 30 minutes to several hours to dissipate sufficiently for pupil tracking. 
Figure 1: Grade 2 diffuse lamellar keratitis

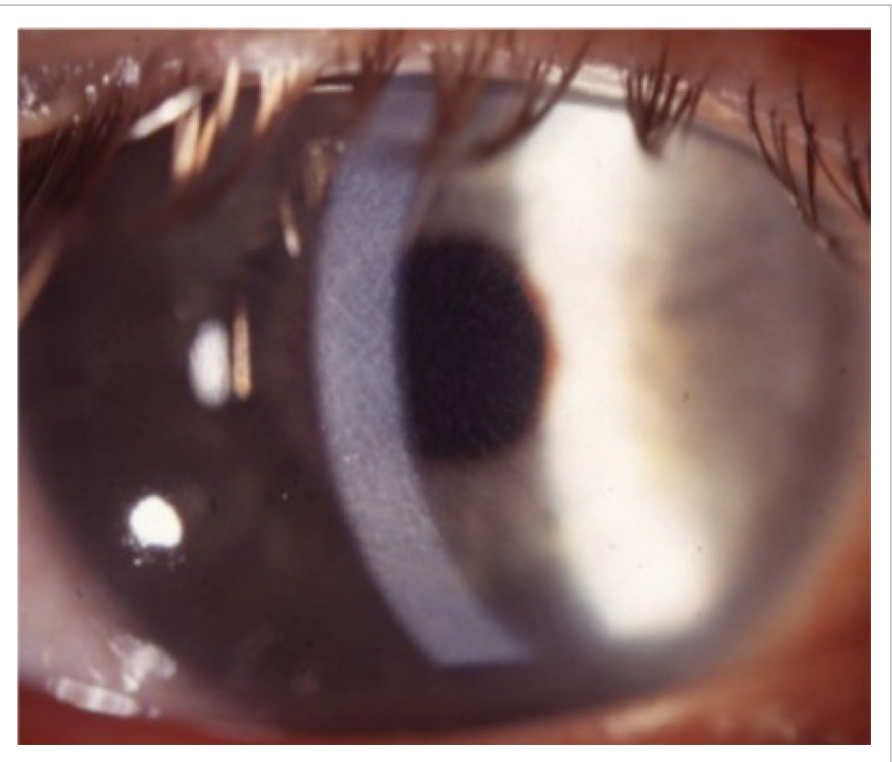

Image courtesy of William Trattler, MD.

\section{Flap tears}

Flap tears during femtosecond LASIK typically occur during flap dissection. Femtosecond laser-created flaps can be more difficult to dissect and lift compared to microkeratome-created flaps. ${ }^{37}$ Thin flaps are at the highest risk of flap tears. One study showed flap tear incidence of $0.5 \%{ }^{35}$ while a similar study showed a $0.4 \%$ rate of tears at the hinge. ${ }^{27}$

For small peripheral flap tears, complete dissection of the flap followed by stromal ablation is acceptable. When a larger flap tear involving the pupillary axis occurs, most surgeons recommend repositioning the flap and aborting the procedure, and considering future surface ablation as a safe way to proceed. For those that proceed with surface ablation and a free flap, a loose anchoring suture to secure the flap after stromal ablation can be used. ${ }^{38}$

\section{Bleeding}

There are two main bleeding complications that can occur with femtosecond LASIK. The first results in a subconjunctival hemorrhage $(\mathrm{SCH})$ and is due to suction. This occurs more frequently (up to 69\% in one study) ${ }^{39}$ with systems that dock on the conjunctiva/sclera such as the IntraLase ${ }^{\circledast}$ (Abbott Medical Optics, CA, USA) rather than platforms that dock on the cornea such as the VisuMax ${ }^{\circledR}$ (Carl Zeiss Meditec, Germany). ${ }^{39}$ Subconjunctival hemorrhage is not visually significant and clears over 1-2 weeks. SCH can be decreased by using slow, controlled use of suction and ensuring centration. The second type of bleeding occurs due to limbal vessel rupture at the edge of the flap. Risk factors include corneal neovascularization from contact lens use, rosacea, atopy, and any other predisposing factors. ${ }^{4}$ Bleeding vessels can interfere with laser ablation and cause irregular astigmatism due to uneven ablation if blood pools within the ablation area. During excimer ablation, sponges can be used to remove blood from the stromal bed. Subsequently replacing the flap after excimer ablation helps to control further bleeding. copious irrigation of residual interface blood during flap repositioning is essential to prevent DLK. ${ }^{5}$ Flap centration and smaller flaps can help prevent bleeding in those with corneal neovascularization.
Figure 2: Grade 3 diffuse lamellar keratitis

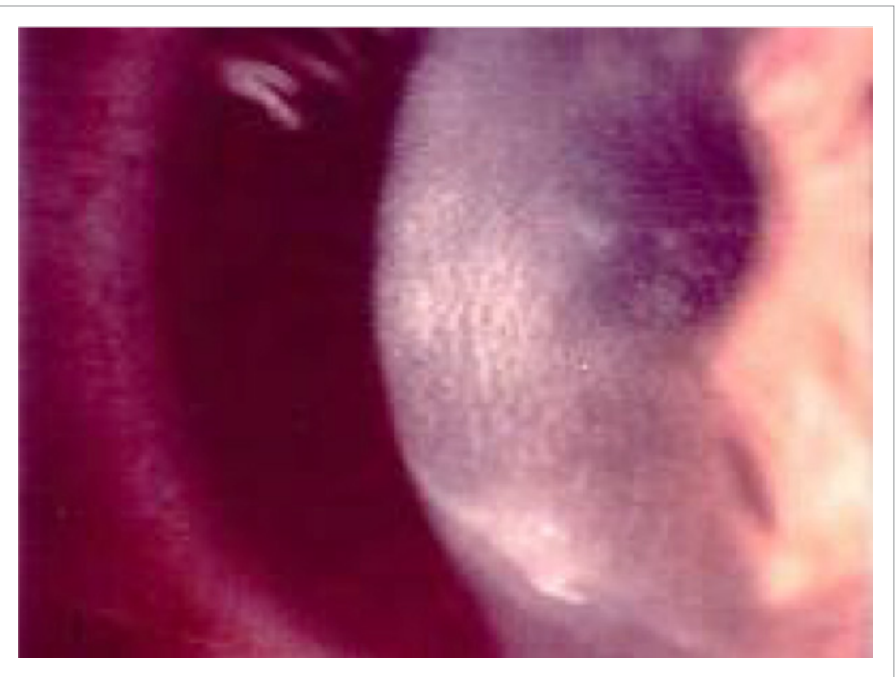

Image courtesy of William Trattler, MD.

\section{Interface debris}

Debris is frequently present in the flap interface following LASIK and is typically due to Meibomian gland secretions, eyelash hairs, fibers from sponges, or talc from gloves. Methods to prevent interface debris include powder-free gloves, moistened gauze, clothes covers for the patient, and scrubs for the surgeon. ${ }^{4}$ During the procedure, adequate irrigation is essential. Prior to repositioning the flap, the surface should be irrigated to remove debris. If noted in the postoperative period and determined not to be infectious or inflammatory, it can be observed. If large amounts of debris are present and visually significant, flap lifting and copious irrigation may be necessary. In our experience, a slit lamp exam shortly after the treatment to look for significant debris with gentle irrigation and flap repositioning at the slit lamp can successfully manage this complication. Larger amounts may require flap lift with a lid speculum in the supine position under the microscope. Mimouni et al. reported rates of flap lift for interface debris to be $0.06 \%{ }^{40}$

\section{Postoperative complications Striae and folds}

After LASIK, striae and folds are a relatively common flap complication and can be characterized as macro or microstriae. Macrostriae are due to misaligned flaps and are often visually significant, whereas microstriae are not typically visually significant. Several causes have been theorized, including dryness that leads to shrinkage, misalignment, and changes in the corneal contour. ${ }^{41}$ Microstriae are typically observed if best corrected visual acuity is not affected. Management of visually significant macrostriae can range from use of a moist microsponge to gently stroke the flap, to lifting and repositioning the flap. In two very large retrospective studies, macrostriae requiring surgical intervention occurred at rates of $0.79-1.17 \% .^{40,42}$ Further techniques include the use of hypotonic solutions to swell the flap, ${ }^{24}$ removal of central epithelium, or suturing the flap. ${ }^{4}$ To prevent striae, marking the flap to ensure correct final positioning is useful. Early intervention leads to best outcomes and we recommend evaluation at the slit lamp immediately following the procedure to ensure appropriate approximation. 
Figure 3: Infectious keratitis

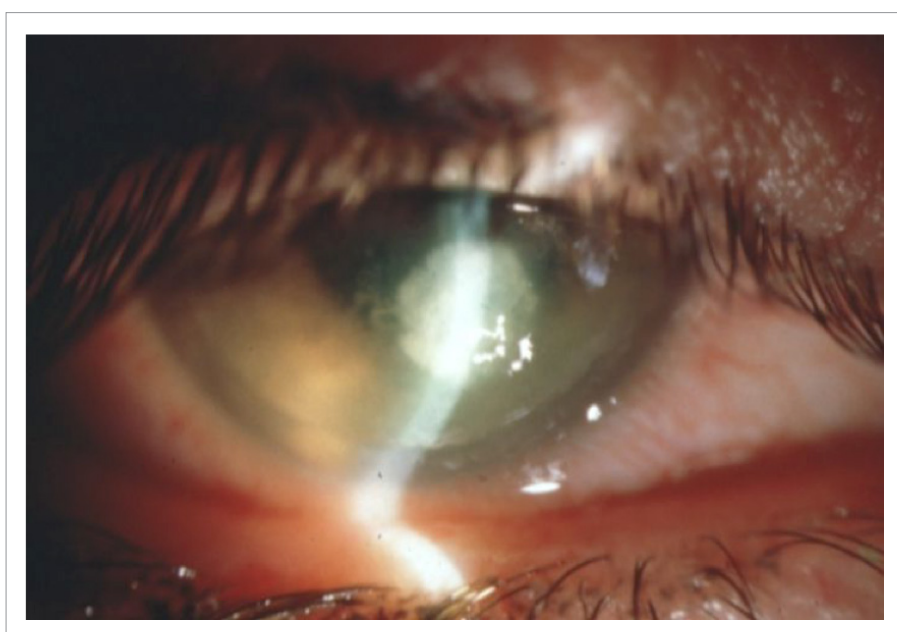

Image courtesy of William Trattler, MD.

\section{Keratitis}

There are several types of keratitis that can affect patients after LASIK including infectious, diffuse lamellar keratitis, pressure-induced stromal keratitis (PISK), and central toxic keratopathy.

\section{Diffuse lamellar keratitis}

DLK, also known as diffuse interstitial keratitis or "sands of the Sahara," is an uncommon, nonspecific sterile inflammatory response that occurs within one week of LASIK. ${ }^{43}$ It presents as inflammatory sterile infiltrate at the interface of the flap and stroma without an anterior chamber reaction. Its incidence in one large study was $0.3 \% .{ }^{8}$ There are four stages of DLK that are based on a system developed by Linebarger et al. ${ }^{44}$ Stage 1 usually presents on day 1 as white granular cells in the periphery with no involvement of the visual axis. Stage 2 (see Figure 1) often presents during days 1-3 with white granular cells in the visual axis. Stage 3 includes clumping of granular cells, haze, and reduced vision. Stage 4 results in stromal necrosis and melt leading to irregular astigmatism and induced hyperopia (see Figure 2). ${ }^{4}$

Some studies have indicated a higher frequency of DLK in femtosecond LASIK cases compared to microkeratome ${ }^{8,27,45}$ with an incidence of Stage 1 or 2 DLK as high as $10.6 \%$ of patients, though all responded to steroids without visual consequence. ${ }^{27}$ New studies using updated femtosecond laser models suggest that the incidence is similar to LASIK performed with the microkeratome. ${ }^{46}$ Patients are often asymptomatic but can present with pain or decreased vision. Factors that increase the risk of DLK are blood in the interface and flap epithelial defects. ${ }^{5}$ If either of these two findings are found, topical corticosteroid use should be increased. Early treatment is paramount with a focus on topical corticosteroids and occasionally oral steroids. In early stages, many surgeons increase topical prednisolone $1 \%$ to every hour and consider oral prednisone. If Stage 3 DLK is present, the flap is lifted, scraped, irrigated, and cultured, with possible application of steroids to the stromal bed. When this condition is recognized, it is important to follow closely to avoid stromal melt. ${ }^{4}$ Late-onset DLK can also happen and has been reported to occur as late as 17 years after LASIK. ${ }^{47}$

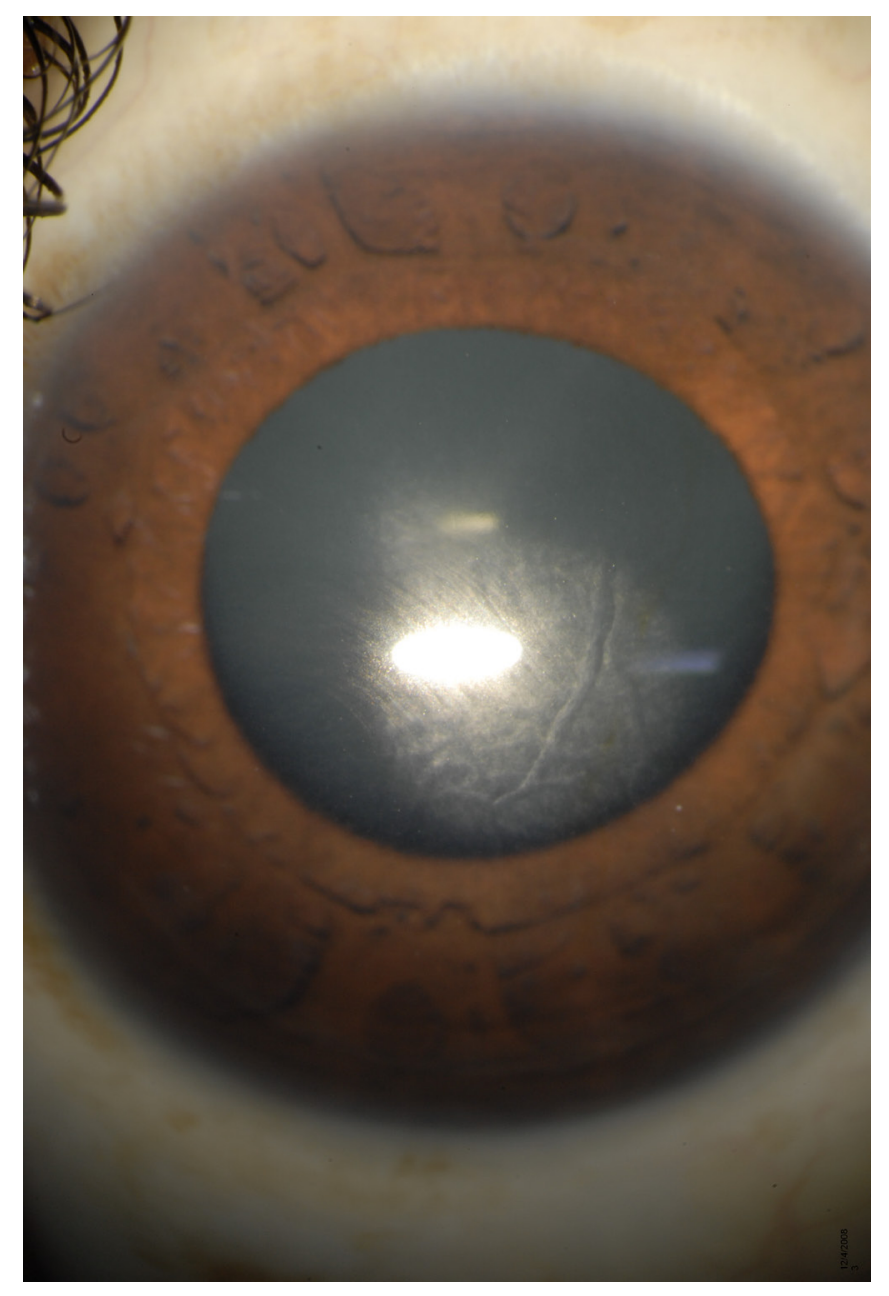

Image courtesy of Joung Y Kim, MD.

\section{Infectious keratitis}

Infectious keratitis is a rare complication following LASIK but one of the most dreaded (see Figure 3). It is not specific to femtosecond laser. Studies have reported an incidence of $0-1.5 \%{ }^{48}$ in LASIK patients and one retrospective case-control study looking at over 500,000 post LASIK patients found an incidence of $0.0046 \%{ }^{49}$ Presenting symptoms can occur acutely or over days to weeks and include decreased vision, erythema, photophobia, and pain. Bacterial keratitis occurs earlier, typically within 3-5 days, while atypical infections such as mycobacteria or fungal present after a few weeks. Treatment is typically with flap lift and irrigation, culture, broad-spectrum antibiotics, and possible flap amputation if necessary..$^{50}$ Prevention includes aseptic technique, good lid hygiene, broad spectrum antibiotics in the early postoperative period, and continuous evaluation of sterile technique and instruments.

\section{Pressure-induced stromal keratitis}

PISK occurs as a result of increased intraocular pressure, typically with prolonged steroid use. In this condition, fluid can accumulate in the interface, leading to falsely low readings which can delay the diagnosis. since the fluid amount is often small, it results in diffuse haziness in 
the interface and stroma, with no obvious fluid layer, though it can occasionally result in a visible fluid cleft separating the stromal cleavage plain. ${ }^{51,52}$ It has been reported to occur acutely in the postoperative setting and as a delayed complication, with some cases occurring years after the original LASIK surgery. 53,54 AS PISK is frequently misdiagnosed as DLK, further use of steroids can exacerbate the clinical condition. Routine IOP checks for patients on prolonged postoperative steroids is essential to diagnose this condition. However, interface fluid can lead to falsely low IOP, necessitating peripheral corneal pressure measurements and maintaining suspicion for the presence this condition. Treatment is typically to remove the steroid and consider a pressure-lowering drop as the IOP will follow suit, resolving the underlying problem. ${ }^{50}$

\section{Central toxic keratopathy}

Central toxic keratopathy is a rare non-inflammatory central corneal opacification that is acute and non-inflammatory in nature (see Figure 4). It occurs within days of stromal ablation procedures. The etiology is unknown but it presents acutely and does not worsen, unlike many of the other interface processes. It presents without pain, which can help distinguish it from DLK. Some surgeons attempt aggressive topical steroid use or flap irrigation, though interventions have not been shown to improve the final outcomes. ${ }^{50,55,56,46}$ The central opacity often spontaneously resolves in 2-18 months without intervention.

\section{Rainbow glare}

Rainbow glare is an optical aberration first noted in 2008 that appears to be more common with specific brands of femtosecond lasers due to diffractive light scattering and irregularities inthe lamellar surface created by the laser. ${ }^{57}$ Rainbow glare typically presents within three months of the procedure, with patients describing bands of 4-12 colors. ${ }^{57,58}$ It has been reported to be most common when the femtosecond flap is created but the excimer laser ablation is aborted. Treatment can be difficult, though symptoms typically do improve over time as well as with ocular surface treatment. Some experts have suggested surface ablation over an aborted flap to reduce symptoms if the patient considers them to be bothersome. ${ }^{4}$

\section{Dry eye}

Dry eye is the most common complication after LASIK surgery. Etiologies include damage to the sensory nerves during flap creation, decreased tear production, decreased blink rate, and injured goblets cells at the limbus. ${ }^{16}$ Nerves typically regenerate with a reduction in dry eye symptoms. Some studies have indicated that dry eye is less common after femtosecond LASIK, $^{16}$ though others have found little difference. ${ }^{59}$ In most cases, extensive lubrication with preservative-free artificial tears is used until the corneal nerves regenerate, which usually takes 6-8 months after surgery. Traditional dry eye treatment strategies including topical cyclosporine A, lifitegrast, punctal plugs, and short-term use of corticosteroids have been used effectively. ${ }^{4}$ Some surgeons recommend using punctal plugs prior to LASIK to mitigate dry eye symptoms while others treat the patient based on the symptoms that are present afterwards.

\section{Dislocated flaps}

Dislocated flaps are a concerning complication of LASIK as the risk is present both early on and throughout life following surgery. Mechanical trauma is the most common cause of a dislocated flap, with minor trauma such as eyelid squeezing and eye rubbing being the most common in the immediate postoperative period. More significant trauma is generally

\section{Figure 5: Epithelial ingrowth image}

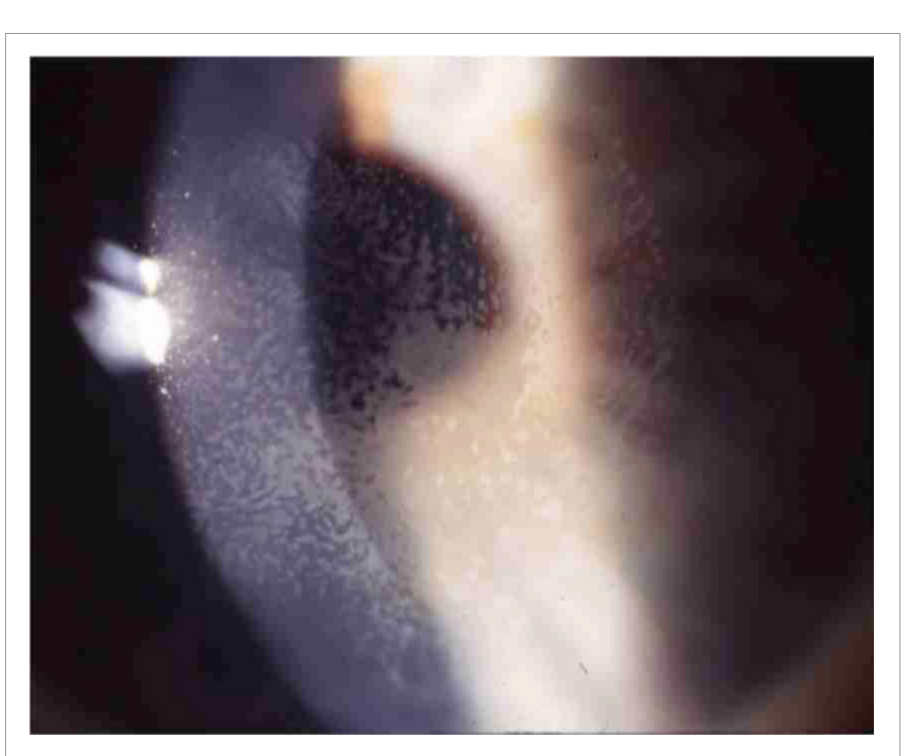

Image courtesy of William Trattler, MD.

the cause in the later postoperative period. Thankfully, rates are low, with early flap dislocation ranging from $0.08-0.012 \%$ in two large retrospective reviews. ${ }^{40,49}$ The frequency of a dislocated flap has decreased with the use of femtosecond flap creation. ${ }^{60,61}$ This is thought to be due to improved flap stability and adhesion strength. ${ }^{5}$

When encountered, a dislocated flap should immediately be repositioned. Overall, the more quickly the flap is repositioned, the better the outcome. The exposed stromal surfaces, both on the flap and on the stromal bed, may need to be scraped to remove any epithelial ingrowth and undergo extensive irrigation. Folds in the flap can be stretched out. Prevention includes use of a shield, contact lens use, and eyelid closure immediately following the procedure. Most surgeons recommend that patients take a nap for a few hours after returning home from the procedure. ${ }^{4}$

\section{Transient light-sensitivity syndrome}

Transient light-sensitivity syndrome is a rare, femtosecond flapassociated complication that results in patients experiencing bothersome photophobia typically 2-6 weeks after LASIK. The visual acuity is unaffected and a slit lamp examination is normal. Several theories exist on its etiology but the most common revolves around insult to the ciliary body and resultant inflammation. ${ }^{17}$ In line with that theory, studies have indicated that using lower energy settings reduces its incidence. Treatment is with aggressive topical corticosteroid use, with initial application up to every hour, followed by a taper. If recalcitrant, oral steroids can be used with good results.

\section{Interface haze}

Since the central corneal epithelial basement membrane remains intact during LASIK, the incidence of interface haze is much less than surface ablation. When it does present in LASIK patients, it typically is due to damage to the epithelial basement membrane such as a buttonhole flap. It also can be seen with PISK. The mainstay of treatment is corticosteroids with fairly rapid resolution. ${ }^{4}$ Interface haze can also be caused by various types of keratitis as described in an earlier section. 


\section{Figure 6: Corneal ectasia}

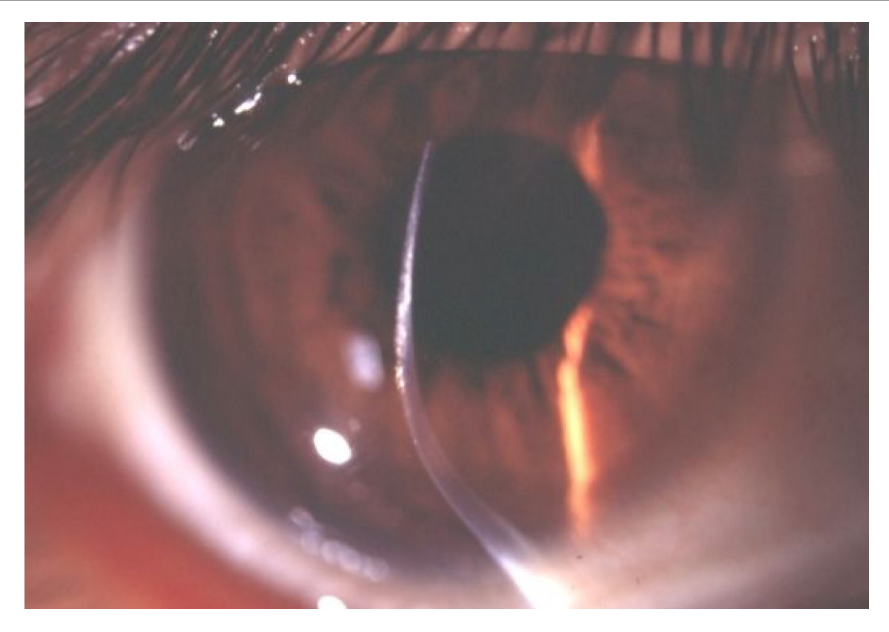

Image courtesy of William Trattler, MD.

\section{Epithelial ingrowth}

Epithelial ingrowth occurs when clusters of epithelial cells insert into the stromal interface resulting in fluorescein staining at the flap edge, a fibrotic demarcation line and, in severe cases, a blockage of nutrient diffusion and keratolysis at the flap edge (see Figure 5). ${ }^{4}$ It can advance circumferentially from the edge and induce irregular astigmatism. While far less common in femtosecond cases compared with microkeratome, ${ }^{4}$ this growth can still occur and typically occurs within two months of the procedure. Most researchers theorize that the epithelial cells are captured in the interface during flap positioning or by back flow of fluid into the flap. There is a higher incidence in epithelial basement membrane dystrophy ${ }^{62}$ or after an enhancement. ${ }^{24}$ Treatment typically includes lifting the flap, copious irrigation, and debriding epithelial cells with a blade on the stromal and flap surface. Most surgeons then apply a bandage contact lens for 24 hours and consider suturing the flap or using fibrin glue to seal the wound. The addition of suturing may decrease rates of recurrence of epithelial ingrowth..$^{63}$ Ethanol can be used during debridement in recurrent cases. ${ }^{5}$ Prevention centers around avoiding epithelial defects and using extreme caution in patients with epithelial basement membrane dystrophy. Steeper side cut angle when creating the flap may decrease the incidence.

\section{Corneal ectasia}

Postoperative corneal ectasia is a rare, but potentially devastating LASIK complication typically associated with a predisposing factor such as forme fruste keratoconus (see Figure 6). During stromal ablation, removal of tissue leads to a weakening of the corneal biomechanics which can lead to ectasia. Other risk factors associated with iatrogenic ectasia include eye rubbing, young age and pregnancy. ${ }^{64}$ Many hypothesize that the thinner, more predictable flaps of femtosecond leads to decreased postoperative corneal ectasia but the research has shown mixed results. ${ }^{37,65}$ Prevention is the most effective approach. Using topographic analysis, various scoring systems, and calculations to identify at-risk patients has been shown to effectively decrease the risk of post-LASIK ectasia. ${ }^{66,67}$ In a large retrospective review of over 30,000 cases between 2007 and 2015, incidence of ectasia was $0.033 \%$ in patients with at least 2 years of follow up. ${ }^{68}$ Management options include collagen crosslinking using ultraviolet light and riboflavin or allogeneic corneal lenticules. ${ }^{42,69}$

\section{Discussion}

The introduction of femtosecond laser technology has created a more reproducible and safe LASIK procedure and its use has increased over time. Microkeratomes have also improved with the rates of various complications, decreasing in both femtosecond and microkeratomeassisted LASIK cases. Over time, techniques, treatments and technologies have continued to improve, resulting in fewer complications.

The next wave of refractive treatment, ReLEX/SMILE (small incision Ienticule extraction; Carl Zeiss Meditec, Germany) has arrived and can only be accomplished with femtosecond technology. Due to this technology and past femtosecond trends, it is our belief that femtosecond laser use will continue to increase.

\section{Conclusions}

Femtosecond laser-assisted flap creation has improved the predictability and thickness of LASIK flaps making LASIK safer. Compared to microkeratome-created flaps, there are fewer complications overall, though femtosecond laser has resulted in a few new complications. It is important for any surgeon performing femtosecond laser-assisted LASIK to be aware of all possible intraoperative and postoperative complications. While the complications are applicable to all femtosecond lasers, it is essential that the surgeon also review the mechanism of suction and flap creation for the specific unit being used to carry out the procedure, as each model has different features that may help reduce certain complications but could predispose the patient to others. In addition to gaining a clear understanding of the mechanisms specific to the laser being used, by reviewing all potential procedural complications and ensuring they have the knowledge to manage any complications that may arise, surgeons can utilize femtosecond laser technology in a way that enables them to perform safe, reliable LASIK. $\square$
1. Barraquer Jl. Basis of refractive keratoplasty - 1967. Refract Corneal Surg. 1989;5:179-93.

2. Pallikaris IG, Papatzanaki ME, Stathi EZ, et al. Laser in situ keratomileusis. Lasers Surg Med. 1990;10:463-8.

3. Buratto L, Ferrari M, Rama P. Excimer laser intrastromal keratomileusis. Am J Ophthalmol. 1992;113:291-5.

4. Shah DN, Melki S. Complications of femtosecond-assisted laser in-situ keratomileusis flaps. Semin Ophthalmology. 2014;29:363-375.

5. dos Santos AM, Torricelli AA, Marino GK, et al. Femtosecond laser-assisted LASIK flap complications. J Refract Surg. 2016;32:52-9.

6. Solomon KD, Fernandez de Castro LE, Sandoval HP, et al. LASIK world literature review: quality of life and patient satisfaction. Ophthalmology. 2009;116:691-701

7. Gimbel HV, Penno EE, van Westenbrugge JA, et al. Incidence and management of intraoperative and early postoperative complications in 1000 consecutive laser in situ keratomileusis cases. Ophthalmology. 1998;105:1839-48.

8. Chang JS. Complications of sub-Bowman's keratomileusis with a femtosecond laser in 3009 eyes. J Refract Surg. 2008:24:S97-101.

9. Yuen LH, Chan WK, Koh J, et al. A 10-year prospective audit of LASIK outcomes for myopia in 37,932 eyes at a single institution in Asia. Ophthalmology. 2010;117:1236-44.e1231

10. Shortt AJ, Allan BD, Evans JR. Laser-assisted in-situ keratomileusis (LASIK) versus photorefractive keratectomy (PRK) for myopia. Cochrane Database Syst Rev. 2013:Cd005135.

11. Bower KS, Weichel ED, Kim TJ. Overview of refractive surgery. Am Fam Physician. 2001;64:1183-90.

12. Lubatschowski H, Maatz G, Heisterkamp A, et al. Application of ultrashort laser pulses for intrastromal refractive surgery. Graefes Arch Clin Exp Ophthalmol. 2000;238:33-9.

13. Flanagan GW, Binder PS. Precision of flap measurements for laser in situ keratomileusis in 4428 eyes. J Refract Surg. 2003;19:113-23.

14. Gil-Cazorla R, Teus MA, de Benito-Llopis L, Mikropoulos DG.
Femtosecond laser vs mechanical microkeratome for hyperopic laser in situ keratomileusis. Am J Ophthalmol. 2011;152:16-21. e12.

15. Chaurasia SS, Luengo Gimeno F, Tan K, et al. In vivo real-time intraocular pressure variations during LASIK flap creation. Invest Ophthalmol Vis Sci. 2010;51:4641-5.

16. Salomao MQ, Ambrosio R, Jr., Wilson SE. Dry eye associated with laser in situ keratomileusis: Mechanical microkeratome versus femtosecond laser. J Cataract Refract Surg. 2009;35:1756-60.

17. Stonecipher KG, Dishler JG, Ignacio TS, Binder PS. Transient light sensitivity after femtosecond laser flap creation: clinical findings and management. I Cataract Refract Surg. 2006:32:91-4.

18. Moshirfar M, Schliesser JA, Chang JC, et al. Visual outcomes after wavefront-guided photorefractive keratectomy and wavefront-guided laser in situ keratomileusis: Prospective comparison. J Cataract Refract Surg. 2010;36:1336-43.

19. Courtin R, Saad A, Grise-Dulac A, et al. Changes to corneal 
aberrations and vision after monovision in patients with hyperopia after using a customized aspheric ablation profile to increase corneal asphericity (Q-factor). J Refract Surg. 2016;32:734-41.

20. Courtin R, Saad A, Guilbert E, et al. Opaque bubble layer risk factors in femtosecond laser-assisted LASIK. J Refract Surg. 2015;31:608-12.

21. Sakimoto T, Rosenblatt MI, Azar DT. Laser eye surgery for refractive errors. Lancet. 2006;367:1432-47.

22. Smadja D, Santhiago MR, Mello GR, et al. Suction loss during thin-flap femto-LASIK: management and beneficial refractive effect of the epithelium. J Cataract Refract Surg. 2012;38:902-5.

23. Tomita M, Watabe M, Nakamura T, et al. Management and outcomes of suction loss during LASIK flap creation with a femtosecond laser. J Refract Surg. 2012;28:32-6.

24. Melki SA, Azar DT. LASIK complications: etiology, management, and prevention. Surv Ophthalmol. 2001;46:95-116.

25. Brenner JE, Mohinani AB, Janbatian HY, Melki S. Early Surface ablation on aborted LASIK flaps. J Refract Surg. 2019;35:121-5.

26. Kezirian GM, Stonecipher KG. Comparison of the IntraLase femtosecond laser and mechanical keratomes for laser in situ keratomileusis. J Cataract Refract Surg. 2004:30:804-11.

27. Moshirfar M, Gardiner JP, Schliesser JA, et al. Laser in situ keratomileusis flap complications using mechanical microkeratome versus femtosecond laser: retrospective comparison. J Cataract Refract Surg. 2010;36:1925-33.

28. Hong JW, Liu JJ, Lee JS, et al. Proinflammatory chemokine induction in keratocytes and inflammatory cell infiltration into the cornea. Invest Ophthalmol Vis Sci. 2001;42:2795-803.

29. Gritz DC. LASIK interface keratitis: epidemiology, diagnosis and care. Curr Opin Ophthalmol. 2011;22:251-5.

30. Liu CH, Sun CC, Hui-Kang Ma D, et al. Opaque bubble layer incidence, risk factors, and clinical relevance. I Cataract Refract Surg. 2014;40:435-40.

31. Wu N, Christenbury JG, Dishler JG, et al. A technique to reduce incidence of opaque bubble layer formation during LASIK flap creation using the VisuMax femtosecond laser. J Refract Surg. 2017:33:584-90.

32. Faktorovich, EG. Femtodynamics: A Guide to Laser Settings and Procedure Techniques to Optimize Outcomes with Femtosecond Lasers. Thorofare, New Jersey, US: Slack Inc, 2009.

33. Rush SW, Cofoid P, Rush RB. incidence and outcomes of anterior chamber gas bubble during femtosecond flap creation for laser-assisted in situ keratomileusis. J Ophthalmol. 2015;2015:542127.

34. Harissi-Dagher M, Todani A, Melki SA. Laser in situ keratomileusis buttonhole: classification and management algorithm. J Cataract Refract Surg. 2008;34:1892-9.

35. Pietila J, Huhtala A, Jaaskelainen M, et al. LASIK flap creation with the Ziemer femtosecond laser in 787 consecutive eyes. J Refract Surg. 2010;26:7-16.
36. Utine CA, Altunsoy M, Basar D. Visante anterior segment OCT in patient with gas bubbles in the anterior chamber after femtosecon laser corneal flap formation. Int Ophthalmol. 2010;30:81-4.

37. Salomao MQ, Wilson SE. Femtosecond laser in laser in situ keratomileusis I Cataract Refract Surg. 2010:36:1024-32.

38. Choi $\mathrm{Cl}$ Melki SA. Loose anchoring suture to secure a free flap after laser in situ keratomileusis. J Cataract Refract surg. 2012:38:1127-9.

39. Rosman M, Hall RC, Chan C, et al. Comparison of efficacy and safety of laser in situ keratomileusis using 2 femtosecond laser platforms in contralateral eyes. J Cataract Refract Surg. 2013;39:1066-73.

40. Mimouni M, Vainer I, Assad N et al. Incidence, indications, and outcomes of eyes needing early flap lifting after LASIK. Cornea. 2018;37:1118-23

41. Biser SA. Flap folds after femtosecond LASIK. Eye contact Lens. 2003;29:252-4

42. Wallerstein A, Gauvin M, Adiguzel E, et al. Clinically significant laser in situ keratomileusis flap striae. J Cataract Refract Surg. 2017;43:1523-33.

43. Rapuano CJ. ILASIK complications and Management. In: Feder R RC. The Lasik Handbook: a Case-Based Approach. Philadelphia, US: Lippincott Williams \& Wilkins, 2007; pg 102-3.

44. Linebarger EJ, Hardten DR, Lindstrom RL. Diffuse lamellar keratitis: diagnosis and management. I Cataract Refract Surg. 2000:26:1072-7.

45. Chen S, Feng Y, Stojanovic A, et al. IntraLase femtosecond laser vs mechanical microkeratomes in LASIK for myopia: a systematic review and meta-analysis. J Refract Surg. 2012;28:15-24.

46. Santhiago MR, Kara-Junior N, Waring GO 4th. Microkeratome versus femtosecond flaps: accuracy and complications. Curr Opin Ophthalmol. 2014;25:270-4.

47. Cheung AY, Anderson BJ, Heidemann DG, Gupta C. Late-onset diffuse lamellar keratitis following laser in situ keratomileusis. Can J Ophthalmol. 2019;54:125-9.

48. Chang MA, Jain S, Azar DT. Infections following laser in situ keratomileusis: an integration of the published literature. Surv Ophthalmol. 2004;49:269-80.

49. Schallhorn JM, Schallhorn SC, Hettinger K, Hannan S. Infectious keratitis after laser vision correction: Incidence and risk factors. J Cataract Refract Surg. 2017;43:473-9.

50. Randleman JB, Shah RD. LASIK interface complications: etiology, management, and outcomes. J Refract Surg. 2012;28:575-86.

51. Hamilton DR, Manche EE, Rich LF, Mlaoney RK. Steroid-induced glaucoma after laser in situ keratomileusis associated with interface fluid. Ophthalmology. 2002:109:659-65.

52. Belin MW, Hannush SB, Yau CW, Schultze RL. Elevated intraocula pressure-induced interlamellar stromal keratitis. Ophthalmology. 2002;109:1929-33.

53. Cabral-Macias J, Garcia-De la Rosa G, Rodriguez-Matilde DF, et al. Pressure-induced stromal keratopathy after laser in situ keratomileusis: Acute and late-onset presentations. J Cataract Refract Surg. 2018;44:1284-90.

54. Kim CY, Jung YH, Lee EJ, et al. Delayed-onset interface fluid syndrome after LASIK following phacotrabeculectomy. BMC Ophthalmol. 2019:19:74.

55. Moshirfar M, Hazin R, Khalifa YM. Central toxic keratopathy. Curr Opin Ophthalmol. 2010;21:274-9.

56. Sonmez B, Maloney RK. Central toxic keratopathy: description of a syndrome in laser refractive surgery. Am J Ophthalmol. 2007;143:420-7

57. Bamba S, Rocha KM, Ramos-Esteban JC, Krueger RR. Incidence of rainbow glare after laser in situ keratomileusis flap creation with a $60 \mathrm{kHz}$ femtosecond laser. I Cataract Refract Surg. 2009:35:1082-6.

58. Krueger RR, Thornton IL, Xu M, et al. Rainbow glare as an optical side effect of IntraLASIK. Ophthalmology. 2008;115:1187-95.

59. Patel SV, McLaren JW, Kittleson KM, Boume WM. Subbasal nerv density and corneal sensitivity after laser in situ keratomileusis: femtosecond laser vs mechanical microkeratome. Arch Ophthalmol. 2010;128:1413-9.

60. Rubinfeld RS, Hardten DR, Donnenfeld ED, et al. To lift or recut: changing trends in LASIK enhancement. J Cataract Refract Surg. 2003:29:2306-17.

61. Clare G, Moore TC, Grills C, Leccisotti A, Moore JE, Schallhorn S. Early flap displacement after LASIK. Ophthalmology. 2011;118:1760-5.

62. Rezende RA, Uchoa UC, Cohen EJ, et al. Complications associated with anterior basement membrane dystrophy after laser in situ keratomileusis. J Cataract Refract Surg. 2004;30:2328-31.

63. Yesilirmak $N$ Chhadva $P$ Cabot $F$ et al. Post-laser in situ keratomileusis epithelial ingrowth: Treatment, recurrence, and long-term results. Cornea. 2018;37:1517-21.

64. Giri P, Azar DT. Risk profiles of ectasia after keratorefractive surgery. Curr Opin Ophthalmol. 2017;28:337-42.

65. Prakash G, Agarwal A, Kumar DA, et al. Femtosecond sub-bowman keratomileusis: a prospective, long-term, intereye comparison of safety and outcomes of 90 - versus $100-\mu \mathrm{m}$ flaps. Am J Ophthalmol. 2011;152:582-90.

66. Santhiago MR, Wilson SE, Hallahan KM, et al. Changes in custom biomechanical variables after femtosecond laser in situ keratomileusis and photorefractive keratectomy for myopia. J Cataract Refract Surg. 2014;40:918-28.

67. Santhiago MR, Smadja D, Gomes BF, et al. Association between the percent tissue altered and post-laser in situ keratomileusis ectasia in eyes with normal preoperative topography. $A m$ J Ophthalmol. 2014;158:87-95.

68. Bohac M, Koncarevic M, Pasalic A, et al. Incidence and clinical characteristics of post LASIK ectasia: A review of over 30,000 LASIK cases. Semin Ophthalmol. 2018:33:869-77.

69. Li M, Zhao F, Knorz MC, Zhou X. Treatment of corneal ectasia by implantation of an allogenic corneal lenticule. J Refract Surg. 2018;34:347-50 